\title{
Ways of Reducing Stress to Improve Children's Eyewitness Testimony
}

\author{
Gaojing Chai ${ }^{1, \dagger}{ }^{\dagger}$ Jiayi $\mathrm{Wu}^{2, *, \dagger}$ \\ ${ }^{1}$ School of Education, Durham University, Durham, United Kingdom \\ ${ }^{2}$ School of Psychology, Rutgers University, New Brunswick, NJ, United States \\ ${ }^{*}$ Corresponding author. Email: jw1198@scarletmail.rutgers.edu \\ ${ }^{\dagger}$ Those authors contributed equally.
}

\begin{abstract}
Child eyewitness testimony has always been a controversial subject. This article discusses some of the factors (such as props and toys, stress, and comfort drawing) that may influence child eyewitness testimony by reviewing the relevant research. More importantly, the association between different music types and child eyewitness testimony is highlighted. It is worth noting that during the interview, music is considered to be an effective factor to reduce stress levels and improve eyewitness testimony. In addition, self preferred calm classical music has proved to be the most effective music type for decompression. It can relieve children's stress levels, improve their cognitive performance and improve eyewitness recall. However, there are two types of music (i.e., atonal music and violent music) that should be avoided in eyewitness interviews. In addition, the limitations of existing research are discussed, and some potential directions for future research are suggested. This study provides research enlightenment for improving the accuracy of children's eyewitness testimony.
\end{abstract}

Keywords: Eyewitness Testimony, Children Eyewitness Testimony, Music Types, Stress.

\section{INTRODUCTION}

Eyewitness testimony is the statement of a victim or bystander who witnessed the occurrence of an incident. It has a pivotal role in all stages of criminal proceedings. A great number of defendants are implicated by eyewitnesses every year, but unfortunately, some eyewitnesses had errors in their memory and testimony. Elizabeth Loftus, a pioneer in the field of eyewitness testimony, has systematically analyzed the factors that influence eyewitness testimony from a psychological perspective. She analyzed not only the time of exposure of the case, stress, and other factors but also the social factors of prejudice and expectations [1]. A further study conducted by Loftus et al. proposed a study that showed that the presence of weapons also leads to a reduction in the accuracy of stated testimony [2]. In addition, past statements about child eyewitness testimony showed that children are more likely to be misreported than adults [3]. The research conducted by Cecci and Bruck further suggested that children are less cognitive and socially experienced than adults. They are unable to understand many social phenomena and are more self-centered. Furthermore, children tend not to pay attention to what they do not understand, resulting in many details being lost [4]. The research conducted by Karen and her colleague highlighted the impact of stress on children's eyewitness testimony [5]. They further discussed the effect of whether it is the stress of experiencing the case or the stress of the recall phase on the accuracy of children's memories. The ways and environments of the eyewitness interview can bring large differences in the quality and results of the testimony. Therefore, this article will discuss some of the factors that may cause children to stress during children's eyewitness testimony and some methods to improve children's eyewitness testimony. Based on the literature, some previous studies and methods on enhancing child eyewitness testimony will be presented. Moreover, some correlations between different types of music on stress and eyewitness testimony will be introduced.

\section{LITERATURE REVIEW}

The current study will present some research on child eyewitness testimony and possible methods to improve child witness testimony. The impact of music on child eyewitness testimony will be highlighted. 


\subsection{Form of the question}

The research conducted by Philip et al. investigated the relationship between child eyewitness testimony and the form of the question. The study was open to preschool children and the experiment consisted of two main parts: viewing and asking questions. The experimenter provided 32 preschoolers with four films, each lasting approximately one minute. Each child was then interviewed individually with eight questions about each film, for a total of 32 questions. The question format was generated by combining affirmative-negative [6]. The result of this study suggested that when objects or events were present in the films, the question format did not affect the accuracy of the children's responses. However, when the object or event was not in the film, question formats such as 'did you see any ...' or 'didn't you see something...' influenced the children's correct responses.

A similar study was conducted by Amanda et al [7]. In their research, the questions consisted of closed-ended questions ('yes' or 'no') and wh-questions (questions require information). The results showed that children were more accurate in answering the wh-questions than the closed questions. Thus, Amanda et al. suggested that children's responses to the questions were influenced by the format of the questions. However, Amanda and her colleague suggested that the experiment only required children to remember and recall the story, and therefore, the level of stress experienced by the child is then reduced compared to the real event. This discussion supports the potential impact of stress levels on child eyewitness testimony.

\subsection{Props and Toys}

Previous experiments have suggested that when children have physical objects or items at the event they are experiencing, the use of physical objects or items as cues during the interview can influence the accuracy of the recall of the event. The research conducted by Salmon et al. introduced the effects of real objects, toys, and no props on the accuracy of children's event reports. Sixtysix children aged 3-5 years were recruited and randomly divided into three groups (with props, with toys, and without props). Children were asked to examine 'sick' bears with a 'doctor' and the experiment involved several interactive actions. Children were interviewed 2-3 days after the experiment [8]. The result showed that props facilitated the accuracy of children's recall of events. However, the supportiveness of props varied according to age. For children aged 5 years, props improved verbal recall, while for children aged 3 years, the effect of props was not significant.

\subsection{Comfort Drawing}

In recent studies of child eyewitness testimony, more researchers have been considering the emotional needs of children. One study, conducted by Poole et al. investigated the relationship between comfort drawing and child witness testimony reports [9]. The experiment was conducted with 219 children $(83.9 \%$ of the children in the previous experiment) aged 5-12 years and consisted of two activities (remote and recent) and interviews. During the interviews, children were randomized into a drawing group and a no-drawing group. However, the researchers found that children in the drawing group also interacted differently with the drawing materials, and the researchers went on to divide the drawing group into three categories - no interaction with the materials, playing with the materials, and drawing. This study aims to create a less stressful environment for children using comfort draw. In this experiment, comfort drawing did not provide a less stressful environment for the children, but it did provide a more emotionally supportive environment for the children, taking into account their emotional needs. However, the result suggested that comfort drawing does not affect child eyewitness reports.

\subsection{Stress}

Several past studies have investigated the relationship between stress and child eyewitness testimony, and studies related to child eyewitness testimony also suggested a relationship between stress levels and testimony accuracy. Research conducted by Karen et al. discussed the relationship between the courtroom environment and the accuracy of the testimony in the environment [5]. Thirty-eight children aged 8 to 10 years were recruited for the experiment and randomized to two conditions (school interview or courtroom interview). The experiment also used the State-Trait Anxiety Inventory to measure the children's level of anxiety [10]. The children were interviewed after watching the staged event. The results of the experiment showed that the courtroom environment influenced the maximum reproduction of the children's witness testimony and increased the children's stress levels. This study and the previous studies mentioned in this paper have highlighted the link between stress, environment, and the accuracy of child witness testimony.

\subsection{Music Types}

Music is a common and effective method used in therapies and interventions. It can improve cognitive performance and can also enhance emotional and physical states. When under the state of stress, listening to music can effectively help relieve it by changing physical arousals, such as increasing parasympathetic nervous system arousal [11], and adjusting mental moods to a more positive state [12]. Therefore, music may be a valid and easily applied method to reduce children's stress during eyewitness testimony acquisition interviews. Although there has been no direct study on the influence 
of music on child eyewitness testimony quality, we can assume the validity of this method through the numerous studies proving that music can efficiently reduce stress. Furthermore, studies have shown that the type of music an individual listens to can cause different impacts [13], so choosing a more effective music type to apply to the interview may lead to a better result (see table 1).

\subsubsection{Classical Music and Non-Classical Music}

Classical music is generally refers to music written in a Western musical tradition, and it usually has highly sophisticated instrumental musical forms. Examples of classical music include symphony, sonata, concerto. In comparison, non-classical music is typically used to describe music in later music styles, such as jazz, rock, pop, blues, and country music. Studies by Burns et al. have shown that classical music is more effective in relieving stress than non-classical music [13]. When two groups respectively listened to classical and non-classical music and then measured the change of their stress level, the state anxiety of the classical music group decreased by $21.36 \%$, while the non-classical music group only decreased by $10.04 \%$. And when self-reporting the stress, the classical music group perceived themselves as more relaxed and less anxious than the non-classical music group. The non-classical group who listened to rock music reported no perceived reduction in stress after listening to music. Therefore, classical music may be the preferred type of music in the interview of child eyewitness testimony. However, it is worth noting that different types of non-classical music may have different influences due to the various branches and styles covered by it. This may be worth further experimentation.

Table 1. Effectiveness of Music types

\begin{tabular}{|c|c|c|c|}
\hline $\begin{array}{c}\text { Type of } \\
\text { Music }\end{array}$ & Descriptive & Type of Music & Descriptive \\
\hline Classical & $\begin{array}{c}\text { State anxiety decreased by } \\
21.36 \%\end{array}$ & Non-Classical & State anxiety decreased by $10.04 \%$ \\
\hline Sedative & $\begin{array}{c}\text { Self-reported decrease of } \\
\text { stress }\end{array}$ & Stimulative & Self-reported increase of stress \\
\hline $\begin{array}{c}\text { Self- } \\
\text { Preferred }\end{array}$ & $\begin{array}{c}\text { Relaxation rate increased in } \\
31.71 \%\end{array}$ & Non-Preferred & Relaxation rate increased in $22.78 \%$ and $18.05 \%$ \\
\hline Atonal & Less self-reported relaxation & Tonal & More self-reported relaxation \\
\hline Violent & Increased aggression & Non-Violent & Increased relaxation and no increased aggression \\
\hline
\end{tabular}

\subsubsection{Sedative Music and Stimulative Music}

Sedative music is typically music that has a flowing melody with few major changes in pitch, strength, or rhythm, which may be similar to that of the resting heart rate. The soothing melody is often used in music therapy to promote a sense of serenity. In contrast, stimulative music usually has a fast tempo, loud volume, and tight rhythm patterns [14]. The study by Jiang et al. had showed that sedative music has more effectiveness in stress reduction than stimulative music [15]. Two groups of participants were exposed to sedative music or stimulative music and then the stress level was measured. Participants who listened to sedative music perceived themselves to be significantly less anxious than did those who listened to stimulative music. Significantly, sedative music can decrease anxiety more than how stimulative music can increase anxiety [13]. As a result, music that are sedative should be more preferred in children's eyewitness testimony interview. To say the least, even if it cannot improve the quality of eyewitness interviews, using sedative music can soothe the emotion of the children who might have experienced harmful cases.

\subsubsection{Self-Preferred Music and Non-Preferred Music}

Interestingly, the preference for music has a significant influence on stress reduction. Many studies have proved that music preference is negatively correlated with state anxiety and positively correlated with relaxation $[11,13,15]$. Music preference can predict anxiety and mediate stress reduction to a certain extent. And listening to self-preferred music is tested more effectively than any particular type of music. Burns et al. showed in the study that listening to self-preferred music is more relaxing than listening to both classical and nonclassical music, with a $31.71 \%$ increase in relaxation in the group listening to self-preferred music, compared to $22.78 \%$ and $18.05 \%$ in the classical and non-classical music groups [13]. Moreover, when music is not preferred, there would be no significant difference in stress reduction when listening to sedative or stimulative music [15]. Therefore, if selecting music type is purely based on effectiveness, self-preferred music may be the first influential factor. However, applying each individual's self-preferred music to eyewitness interviews can require complex premise work and testing. It is not as convenient and efficient as directly applying other tested effective music types. Whether this step is worthwhile might be a further investigable area. 


\subsubsection{Atonal Music and Tonal Music}

Compared with common tonal music, atonal music is music that lacks a tonal center, or key. It can get away from all the rules of standard, key-based music and experiment with new sounds. Studies by Smith and Morris have shown that atonal music is less effective than tonal music in self-reported relaxation. The stress of six groups was measured after listening to different types of music, including four tonic music like classical, romantic, and easy-listening music, as well as a piece of atonal music. In the self-report questionnaire, the atonal music group scored 4.83 on relaxation when other tonal music groups scored 5.97 on average. The result revealed that the atonal music was the only one that led to significantly less relaxation and was liked significantly less than any other type of music [16]. Therefore, when applying music in children's eyewitness interviews, atonal music should not be an effective consideration in normal cases.

\subsubsection{Violent Music and Non-Violent Music}

Violent music is a type of music seen more often in the modern world. It is music that contains aggressive or hostile lyrics, melodies, and vibes. Five experiments conducted by Anderson et al. testing the effect of violent music and non-violent music proved that violent songs can lead to more aggressiveness than non-violent songs [17]. Measuring tasks showed that the group of participants who listened to violent music had more aggressive and hostile thoughts and feelings, even when not provoked. Although some music is effective in reducing stress, other music can also increase stress and aggressiveness. Increased stress and aggression are certain factors to be avoided during interviews with child eyewitness testimony. It might even trigger negative memories and emotions in some children. Therefore, it is crucial to avoid using music that contains violent elements during children's eyewitness interviews.

\subsection{The Advantage of Music}

Music has several potential advantages over the influences of other methods previously studied. Firstly, music, as a non-verbal message, has less distracting information than questions posed verbally. Secondly, the validity of music is similar for all ages, whereas, in the article above, the supportiveness of toys and props can be influenced by age. Furthermore, different types of music have different effects on stress levels, such as sedative music can significantly reduce stress levels. As with comfort drawing, the experiment was conducted to maximize the emotional needs of the participants, playing sedative music during an interview with a child may potentially reduce the child's level of stress and thus enhance recall of the event. Similarly, classical and selfpreferred music may also potentially reduce stress levels. Thirdly, applying music in child eyewitness interviews is easier to manipulate and control than other methods. The child can automatically hear the background music during the interview, and does not require any voluntary engagement of children.

\section{LIMITATIONS AND FUTURE IMPLICATIONS}

This study has several limitations that require further study. Firstly, controlling for music preference, the large moderator for the effectiveness of stress reduction, may require a lot of experimentation. Studies have shown that the same piece of music may have different levels of stress adjustment for each individual based on music preference. Currently, there is no standard way to test music preferences, usually through questionnaires and self-reports. However, for relatively young eyewitnesses, knowing and providing accurate information about their musical preferences can sometimes be difficult. Thus, although music is generally an easy method to apply during the interview, a more efficient way to collect each child eyewitness's music preferences is needed to be developed. Secondly, while music has a stress-reducing function, in some situations it can also trigger negative emotions. There is an individual difference in the sensitivity and like of sad music. Variable factors such as rumination, absorption, and music empathy can all affect the influence of music on each individual [18]. As some eyewitnesses might have negative experiences with certain pieces or types of music, there might be a risk of triggering negative emotions or even trauma. Therefore, if music is to be applied in eyewitness interviews, it is necessary to be cautious and clear in advance whether the child witness had any negative experience with music to avoid unintentional harm.

When analyzing and discussing previous studies of child eyewitness testimonies and different musical types, some possible research directions and implications for future study are founded. Firstly, it is possible to conduct a direct study on the effect of music on children's eyewitness testimony. Further refinements can be made to the music duration, loudness, and ways of displaying the music. It is also possible to draw on the experiments of Karen et al. and use the State-Trait Anxiety Inventory, or more advanced electronic devices, to accurately measure the children's level of stress during the experience of the event and the interview. There is a great amount of potential clinical implications for reducing stress through music during interviews. For example, children who have had witnessed or experienced a bad event (such as sexual abuse or school bullying) can be provided with a more comfortable environment to be interviewed to meet their emotional needs. Classical, sedative, or self-preferred music may help the child to restore memories to the greatest extent possible. 


\section{CONCLUSION}

In conclusion, this paper discusses some of the factors that influence the quality of child eyewitness testimony. Two of the studies confirm the influence of question format on eyewitness testimony, with children being more accurate in answering suggestive and wh-questions than other forms of questions. Secondly, toys and props have also been shown to facilitate children's eyewitness testimony reports. However, this effect varies with age. The impact of stress on children's eyewitness testimony is further discussed, and research confirms that environment and stress can influence children's maximum recall of events. Comfort drawing is discussed as a possible factor that may reduce stress levels and increase the accuracy of testimony. However, the results of the experiment confirmed that comfort drawing did not have a significant effect on the accuracy of witness testimony. Significantly, music is a factor that is considered effective in reducing stress levels during the interview and improving eyewitness testimony. Moreover, self-preferred sedative classical music is proved to be the most effective music type in stress reduction. It can relieve the stress level of children and increase their cognitive performance, to improve eyewitness recall. However, two types of music should be avoided using in eyewitness interviews. Using atonal music or violent music during the interview might trigger negative feelings and thoughts of the children such as aggressive and unpleasant emotions. In a word, music is an effective way to reduce stress and improve child eyewitness testimony and is also worth further studying.

\section{REFERENCES}

[1] C. J. Brainerd, V. F. Reyna, Reliability of Children's Testimony in the Era of Developmental Reversals. Developmental review , 2012, 32(3), pp. 224-267. DOI: https://doi.org/10.1016/j.dr.2012.06.008

[2] S. J. Ceci, and M. Bruck. Suggestibility of the child witness: a historical review and synthesis. Psychological bulletin 1993, 113(3), pp. 403-39. DOI: https://doi.org/10.1037/0033-2909.113.3.403

[3] E. F. Loftus, G. R. Loftus, \& J. Messo, Some facts about "weapon focus.". Law and Human Behavior. 1987, 11(1), pp.55-62. DOI: https://doi.org/10.1007/BF01044839

[4] E. F. Loftus, Eyewitness testimony. Cambridge, MA: Harvard Univ. Press. 1979.

[5] K. J. Saywitz, R. Nathanson, Children's Testimony And Their Perceptions Of Stress In And Out Of The Courtroom. Child Abuse \& Neglect, 1993, 17, (5), pp. 613-622. DOI: https://doi.org/10.1016/01452134(93)90083-h.
[6] P. S. Dale, E. F. Loftus, \& L. Rathbun, The Influence Of The Form Of The Question On The Eyewitness Testimony Of Preschool Children. Journal Of Psycholinguistic Research, 1978, 7(4), pp. 269-277. DOI: https://doi.org/10.1007/bf01068110.

[7] A. H. Waterman, M. Blades, and C. Spencer, Interviewing Children And Adults: The Effect Of Question Format On The Tendency To Speculate. Applied Cognitive Psychology, 2001, 15(5), pp. 521-531. DOI: https://doi.org/10.1002/acp.741

[8] K. Salmon, S. Bidrose, M. E. Pipe, Providing Props To Facilitate Children'S Event Reports: A Comparison Of Toys And Real Items. Journal Of Experimental Child Psychology, 1995, 60(1), pp. 174-194.

DOI: https://doi.org/10.1006/jecp.1995.1037.

[9] C. D. Speilberger, State-trait anxiety inventoryfor children. Palo Alto, 1973 CA: Consulting Psychologist Press, Inc.

[10] P. D. Ann, and J. J. Dickinson, Comfort Drawing During Investigative Interviews: Evidence Of The Safety Of A Popular Practice. Child Abuse \& Neglect, 2014, 38(2), pp. 192-201. DOI: https://doi.org/10.1016/j.chiabu.2013.04.012.

[11] E. Labbé, N. Schmidt, J. Babin, \& M. Pharr, Coping with stress: The effectiveness of different types of music. Applied Psychophysiology and Biofeedback, 2007, 32(3-4), 163-168. DOI: https://doi.org/10.1007/s10484-007-9043-9

[12] N. Yehuda, Music and Stress. Journal of Adult Development, 2011, 18(2), 85-94. DOI: https://doi.org/10.1007/s10804-010-9117-4

[13] J. L. Burns, E. Labbe, B. Arke, K. Capeless, B. Cooksey, A. Steadman, \& C. Gonzales, The effects of different types of music on perceived and physiological measures of stress. Journal of Music Therapy, 2002, 39(2), 101-116. DOI: https://doi.org/10.1093/jmt/39.2.101

[14] C. L. Pelletier, The effect of music on decreasing arousal due to stress: A meta-analysis. Journal of Music Therapy, 2004, 41(3), 192-214. DOI: https://doi.org/10.1093/jmt/41.3.192

[15] J. Jiang, D. Rickson, \& C. Jiang, The mechanism of music for reducing psychological stress: Music Preference as a mediator. The Arts in Psychotherapy, 2016, 48, 62-68. DOI: https://doi.org/10.1016/j.aip.2016.02.002

[16] C. A. Smith, \& L. W. Morris, Differential effects of stimulative and sedative music on anxiety, concentration, and performance. Psychological 
Reports, 1977, 41(3), pp. 1047-1053. DOI: https://doi.org/10.2466/pr0.1977.41.3f.1047

[17] C. A. Anderson, N. L. Carnagey, \& J. Eubanks, Exposure to violent media: The effects of songs with violent lyrics on aggressive thoughts and feelings. Journal of Personality and Social Psychology, 2003, 84(5), pp. 960-971. DOI: https://doi.org/10.1037/0022-3514.84.5.960

[18] S. Garrido, \& E. Schubert, Adaptive and maladaptive attraction to negative emotions in music. Musicae Scientiae, 2013, 17(2), pp. 147-166. DOI: https://doi.org/10.1177/1029864913478305 